\title{
A problemática ambiental decorrente dos resíduos sólidos gerados no processo produtivo do queijo
}

\section{The environmental problems resulting from solid waste generated in the production process cheese}

\author{
Michel Almeida da Silva ${ }^{1}$, Simone Nóbrega Ribeiro Almeida ${ }^{2}$, Ricardo Ricelli Pereira de Almeida ${ }^{3}$, Eclivaneide Caldas de \\ Abreu Carolino ${ }^{4}$, Diêgo Lima Crispim 5 .
}

\begin{abstract}
Resumo: O processo de fabricação e comercialização de queijo, sejam eles em grandes agroindústrias ou de modo artesanal em pequenas propriedades rurais, é parte importante na economia brasileira, sobretudo para algumas regiões, a exemplo da região nordeste do Brasil. O objetivo deste trabalho foi efetuar uma caracterização preliminar da produção de queijo, enfatizando o levantamento de suas relações com o meio ambiente e os possíveis aspectos e impactos ambientais decorrentes da produção de queijo. Para tanto, utilizou-se como processo metodológico uma revisão bibliográfica da problemática em estudo a fim de se obter a maior quantidade possível de informações, além de fazer uma correlação com estudos que traz alternativas para o aproveitamento do principal efluente gerado no processo produtivo do queijo, que é o soro derivado do leite. O soro do leite é um subproduto de alto potencial poluidor, e as empresas perceberam que agregando valor a esse subproduto derivado do leite tem-se uma alternativa viável economicamente, além da redução dos custos com o tratamento de efluentes. Destacando assim, a necessidade de conscientização dos empresários deste segmento, bem como da instalação e/ou adequação de sistemas de tratamento eficientes dos resíduos e efluentes gerados em todas as etapas do processo, haja vista o alto potencial poluidor e impactante desta atividade.
\end{abstract}

Palavras-chave: Agroindústria. Leite. Efluentes. Impactos ambientais.

\begin{abstract}
The process of manufacturing and marketing of cheese, whether in big agribusiness or artisanal way in small farms, is an important part in the Brazilian economy, especially for some regions such as the northeast region of Brazil. The objective of this study was to perform a preliminary characterization of cheese production, emphasizing raising its relations with the environment and potential environmental aspects and impacts of the cheese production. For this purpose, it was used as a methodological process a literature of the problematic review of study in order to obtain the largest possible amount of information, and make a correlation with studies that brings alternatives to the use of the main wastewater generated in the production of the cheese making process, which is derived from milk serum. Whey is a high pollution potential by-product, and companies have realized that adding value to this byproduct derived from milk has an economically viable alternative, in addition to reducing the costs of treating effluents. Highlighting thereby the need for awareness of entrepreneurs in this segment as well as the installation and / or suitability of efficient treatment systems for waste and effluents generated at all stages of the process, given the high pollution potential and impacting this activity.
\end{abstract}

Key words: Agrobusiness. Milk. Effluents. Environmental impacts.

\footnotetext{
*Autor para correspondência

Recebido para publicação em 10/09/2015; aprovado em 11/10/2015

$1^{*}$ Engenheiro Ambiental, Mestrando em Sistemas Agroindustriais, UFCG/CCTA, Pombal-PB; (83) 999814739; E-mail: micheldmalmeida@ hotmail.com

${ }^{2}$ Engenheira Ambiental, Mestranda em Sistemas Agroindustriais, UFCG/CCTA, Pombal-PB; E-mail: simonenobrega2@gmail.com

${ }^{3}$ Engenheiro Ambiental, Mestrando em Sistemas Agroindustriais, UFCG/CCTA, Pombal-PB; E-mail: ricelli2008@ bol.com.br

${ }^{4}$ Professora da Faculdade Santa Maria, Cajazeiras-PB, Mestranda em Sistemas Agroindustriais, UFCG/CCTA, Pombal - PB; E-mail: eclivaneide@hotmail.com

${ }^{5}$ Engenheiro Ambiental, Mestrando em Sistemas Agroindustriais, UFCG/CCTA, Pombal-PB; E-mail: diegolc_85@hotmail.com
} 


\section{INTRODUÇÃO}

O Brasil é um dos maiores produtores de leite bovino, ocupando a quinta posição na produção mundial, o que corresponde a 5\% desta produção em escala global, destacando-se nessa produção as regiões Sudeste, Sul e Nordeste (NADAI et al., 2013).

Dentre as atividades agroindustriais, este setor é bastante diversificado, haja vista o grande leque de produtos derivados do leite produzidos pelas indústrias de laticínios, quais sejam: leite pasteurizado, leite desnatado, queijos, cremes de leite, manteiga, leite condensado, doce de leite, iogurte, bebidas fermentadas, sorvetes dentre outros, além de possuir grande relevância no que tange aos aspectos econômicos e sociais (JERÔNIMO et al., 2012).

Destas atividades supracitadas, uma parcela bastante significativa da produção de leite é destinada a indústria queijeira, considerada importante segmento do setor lácteo, cuja produção de queijos é bem distinta, apresentando diversos e finos tipos, podendo variar de acordo com a região e sua cultura (MOREIRA; SARAIVA; MAGALHÃES, 2012).

É importante ressaltar o fato da fabricação de queijos não ser uma atividade apenas industrial, tendo em vista que em algumas regiões a fabricação é realizada de maneira artesanal, principalmente em pequenas localidades ou propriedades rurais de acordo com a Associação Brasileira das Indústrias de Queijo (ABIQ), leva em consideração algumas tradições e costumes culturais no processo produtivo.

A fabricação e comercialização deste produto é parte importante na economia brasileira, sobretudo para algumas regiões, a exemplo da região nordeste do país (MATTOS; FIGUEIREDO; CAVALCANTE, 2013).

É sabido que na confecção de $1 \mathrm{~kg}$ de queijo, são gerados cerca de 9 litros de soro de leite, este que é um subproduto da indústria queijeira altamente prejudicial ao meio ambiente, quando destinado de forma incorreta, ou seja, lançado in natura no solo e nos corpos hídricos, tendo em vista que este efluente é considerado cem vezes mais poluentes que os esgotos domésticos (COSTA et al., 2014; PAULA et al., 2012). O potencial poluidor desse efluente se dá principalmente em virtude da elevada carga de matéria orgânica, que pode ocasionar poluição no solo, comprometendo sua estrutura físico-química, poluição nos mananciais, provocando a geração de odores desagradáveis, além de contribuir com a intensificação do processo de eutrofização dos mesmos, sobretudo no ambiente aquático com ausência ou pouca ocorrência de correntezas (COSTA et al., 2014; FARIZOGLU et al., 2007).

Em grandes indústrias de queijarias, além deste resíduo ora citado, existem outros aspectos ambientais que devem ser considerados, tais como as embalagens, os papéis, papelão, dentre outros resíduos que são gerados no processo produtivo (MAGANHA, 2006).

Ao revés, estes aspectos ambientais quase não ocorrem quando se trata de fabricação em pequenas propriedades e de modo artesanal.

No que se refere ao aspecto econômico, o custo no tratamento dos efluentes gerados no processo produtivo das queijarias torna-se bastante oneroso, colaborando, desta forma, com a falta e/ou ineficiência destes sistemas de tratamento na maioria das indústrias desse segmento, de modo especial, nas de pequeno porte e de produção artesanal.

Para tanto o objetivo deste trabalho é efetuar uma caracterização preliminar acerca da produção de queijo, priorizando o levantamento de suas relações com o meio ambiente e os possíveis impactos ambientais negativos causados pela produção de queijo.

\section{METODOLOGIA}

O trabalho foi produzido na perspectiva descritiva, visto que foi realizado um levantamento bibliográfico objetivando a revisão de literatura na qual se compreende das seguintes etapas: Identificação do tema; Formulação da questão de pesquisa; Elaboração dos critérios de inclusão e exclusão de trabalhos científicos; Construção de instrumento para coleta de dados relevantes dos trabalhos científicos encontrados; Avaliação e análise dos trabalhos científicos selecionados na pesquisa;

Interpretação e discussão da temática.

\section{REVISÃO BIBLIOGRÁFICA}

\section{A INDÚSTRIA DO QUEIJO}

Estima-se que a produção do queijo teve origem há aproximadamente oito mil anos, no Iraque, por isso é considerado o alimento processado mais antigo da história (RESENDE, 2010).

Alimento este que é tido como completo, devido seu valor nutricional, cujos principais componentes são água, gordura, proteínas, sais minerais e vitaminas, podendo esta composição variar de acordo com o tipo e a matéria-prima utilizada no processo produtivo (FRANCO, 2006).

De acordo com Associação Brasileira das Indústrias de Queijos (ABIQ), em 2011 o país produziu 867 mil toneladas deste alimento, aumentando a produção em $9,4 \%$ com relação a 2010 .

Destaca-se ainda que anualmente o Brasil produz cerca de 488 mil toneladas de queijos. Produção essa que é bastante diversificada, dada à fabricação de queijos nacionais e de nacionalidade estrangeira, que constitui a maior parcela.

Dos vinte e sete Estados brasileiros, a produção de queijo se dá em 23, em sua maioria em Estados localizados na região Sudeste (58\%), seguido da região Sul (23\%). Sendo o Estado de Minas Gerais o primeiro no ranking em produção de queijos no Brasil com cerca de $45 \%$ da produção, seguido dos Estados do Paraná e São Paulo com 13\% e $8 \%$ respectivamente (COSTA, 2014).

O Ministério da Agricultura, do Abastecimento e da Reforma Agrária, em sua Portaria ${ }^{\circ}$ 146, de 7 de março de 1996, que dispõe sobre Regulamentos Técnicos de Identidade e Qualidade dos Produtos Lácteos define o queijo como sendo:

Produto fresco ou maturado obtido por separação parcial do soro de leite reconstituído (integral, parcial ou totalmente desnatado) ou soros lácteos coagulados pela ação física do coalho, de enzimas e bactérias específicas, de ácidos orgânicos, isolados ou combinados, todos de qualidade apta para uso alimentar, com ou sem agregação de substâncias alimentícias ou especiarias e/ou condimentos, aditivos especificamente indicados, substâncias aromatizantes e corantes (BRASIL, 1996). 
Atualmente são fabricados no Brasil uma ampla variedade de queijos, variedade esta que vai de encontro as próprias tradições e concepção cultural. No entanto, alguns queijos são produzidos inspirados nos conhecimentos queijeiros advindos de outros países como França, Dinamarca, Itália, Inglaterra e Estados Unidos. Conhecimentos estes que foram sendo adaptados às características e à oferta das bacias leiteiras das regiões brasileiras e se adequando as primazias do consumidor brasileiro (ABIQ, 2014).

\section{PROCESSO PRODUTIVO DO QUEIJO}

Para Ruas (2012) o processo produtivo do queijo, independente do tipo, envolve uma série de procedimentos que tem em comum alguns passos, estes que podem ser descritos a seguir e posteriormente resumido na Figura 1.

I. O leite empregado no processo produtivo do queijo é conservado a baixa temperatura em recipientes de aço inoxidável;

II. Em Seguida é encaminhado para o processo de coagulação onde é acrescido o coalho microbiano ou vegetal;

III. Após certo tempo, o leite coagulado produz a coalhada, essa é cortada e transformada no queijo e em soro;

IV. O soro produzido na etapa anterior é utilizado no fabrico de requeijão, no qual resulta o segundo soro ou sorelho;

V. A água de lavagem das instalações e equipamentos é chamada água residual da indústria do queijo (ARIQ).

Figura 1 - Fluxograma simplificado do processo produtivo do queijo

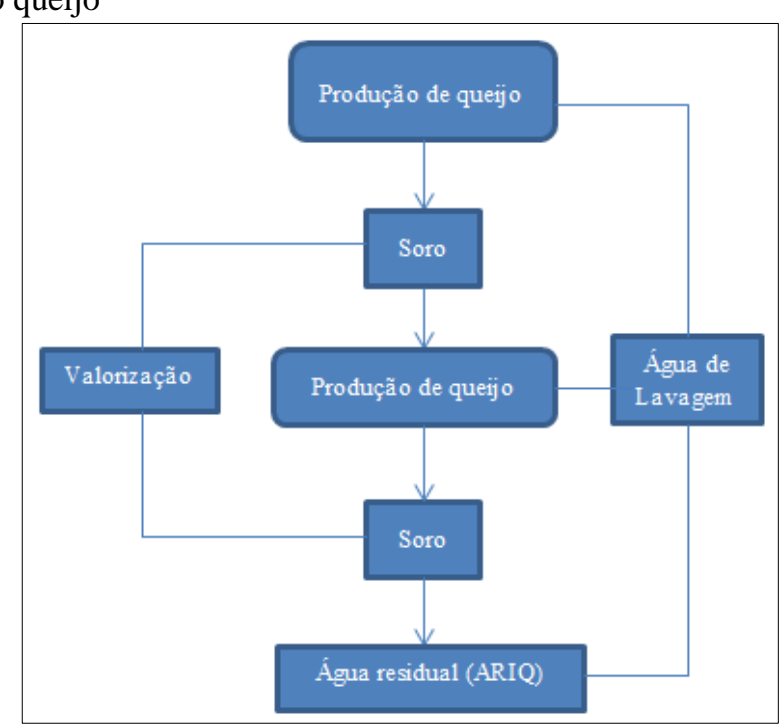

Fonte: RUAS, 2012.

\section{ASPECTOS E IMPACTOS AMBIENTAIS NO PROCESSO PRODUTIVO DO QUEIJO}

Diversas são as interpretações dadas às definições de aspecto e impacto ambiental, para tanto, necessário se faz conceituá-las para melhor compreensão da temática em estudo.

Conforme a norma NBR ISO 14.001, entende-se por aspecto ambiental "o elemento da atividade, produtos ou serviços de uma organização que pode interagir com o meio ambiente", (ABNT, 2004).
No que diz respeito a impacto ambiental a Resolução CONAMA No ${ }^{\circ} 001$, de 23 de janeiro de 1986, em seu artigo $\mathrm{n}^{\circ}$ 1 define o mesmo como sendo:

Qualquer alteração das propriedades físicas, químicas e biológicas do meio ambiente, causada por qualquer forma de matéria ou energia resultante das atividades humanas que, direta ou indiretamente, afetam:

I - a saúde, a segurança e o bem-estar da população;

II - as atividades sociais e econômicas;

III - a biota;

IV - as condições estéticas e sanitárias do meio ambiente;

$\mathrm{V}$ - a qualidade dos recursos ambientais.

Maganha (2006) destaca em seu estudo que os principais impactos ambientais oriundos do processo produtivo na indústria de laticínios estão direta ou indiretamente relacionados com alguns dos seguintes aspectos:

\section{O elevado consumo de água}

Este representa o recurso natural com maior utilização no setor, pois seu uso está normalmente ligado à garantia das qualidades sanitárias e de higiene necessárias.

O consumo desse recurso está inteiramente conexo às operações de limpeza do ambiente de trabalho, lavagem da massa láctea, além do resfriamento e geração de vapor. Estima-se que, em média o consumo de água no processo produtivo de queijo varia entre 1,0 e 6,0 litros $/ \mathrm{kg}$ de leite recebido.

\section{Geração de efluentes}

Os efluentes da indústria do queijo caracterizam-se por apresentar uma elevada concentração orgânica, constituindo assim no principal aspecto ambiental do setor.

No tocante a quantidade de efluentes gerados, estima-se um valor médio de quatro litros de resíduo líquido para cada litro de leite processado.

Estes efluentes são resultantes principalmente da lavagem e limpeza de caminhões, tanques, máquinas e equipamentos diretamente envolvidos no processo produtivo, além de vazamentos, derramamento e operações ineficientes de equipamentos, que por ventura venham a gerar perdas no processo e descarte de produtos, tais como soro ou leite ácido;

\section{Elevado consumo de energia}

Este aspecto está relacionado à garantia de qualidade dos produtos, haja vista que estes necessitam ser armazenados em ambientes refrigerados, além da iluminação, ventilação e operação dos equipamentos;

\section{Geração de resíduos sólidos}

Caracterizam-se pelos resíduos gerados fora do processo industrial propriamente dito, a exemplo papéis, produtos descartáveis, restos de embalagens, material de análises físico - químico, microbiológicas, entre outros;

\section{Emissões atmosféricas}


Estas fontes poluidoras são decorrentes dos gases liberados a partir da queima de combustíveis ou operações com caldeiras.

Para Ruas (2012) quando há uma alteração no aspecto estético, composição ou na forma do meio físico, sucede a poluição. Por sua vez, a partir do momento que existir a mínima ameaça à saúde da população, da flora ou da fauna o ambiente é considerado contaminado.

Ainda ressalva que o lançamento inadequado de resíduos, seja sólido, líquidos ou gasosos, originados das mais diversas fontes acarreta alterações nas características dos corpos hídricos, do solo e do ar, estes que podem afetar negativamente o meio ambiente.

Além da poluição ambiental, o descarte do soro é também um desperdício de material proteico e outros nutrientes, uma vez que retém cerca de 55\% dos nutrientes do leite (BIASUTTI, 2006; OZMICHI, 2007; SUZART; DIAS, 2007).

O soro é o liquido obtido da precipitação de gorduras e caseína do leite durante o processo de fabricação de queijos, representa 85 a $90 \%$ do volume de leite e retém $55 \%$ de seus nutrientes, dentre eles a lactose $(4$ a $5 \%)$ e proteínas $(0,6$ a 0,7\%) (COSTA, 2014; SARAIVA et al., 2012; SERPA, 2009).

\section{SORO DO LEITE}

Sabendo que o soro de leite é a principal fonte poluidora, muitos estudos vêm sendo desenvolvidos com o intuito de encontrar maneiras de minimizar os impactos ambientais negativos oriundos deste subproduto.

Importância deve ser dada aos avanços das pesquisas científicas, uma vez que, com estas, pôde-se averiguar que o soro possui qualidades nutricionais importantes, e o que antes era desperdiçado, atualmente é utilizado para alimentação animal (mais especificamente alimentação de suínos), passando a ser reincorporado na cadeia produtiva láctea, na forma de alguns produtos (BARANA et al., 2012).

Partindo deste pressuposto é possível mencionar alguns estudos que traz alternativas para o aproveitamento do soro de leite, a exemplo do aproveitamento de soro para a fabricação de doce de leite pastoso, proposto por Batista et al. (2013), no qual foi comparado o doce padrão com $100 \%$ de leite com outros doces de leite fabricados com soro, variando apenas a concentração de soro para cada doce. Os resultados foram surpreendentes, pois os doces de leite com substituição parcial de leite por soro, nas proporções de 10,15 e $20 \%$, tiveram aceitação semelhante a da amostra padrão.

De forma similar de reaproveitamento do soro, Nadai et al. (2013) procurou mostrar que o uso do permeado de soro, é fonte de matéria-prima (barata e alternativa) para a produção de biomassa de leveduras e suas frações em grande escala.

Martins et al. (2008) destacam em seu estudo a importância do soro de queijo e avalia o seu uso sobre o desenvolvimento de suínos em crescimento, utilizando níveis de substituição de $0 \% ; 10 \% ; 20 \%$ ou $30 \%$ da matéria seca das rações à base de milho e farelo de soja com $15 \%$ de proteína bruta, por matéria seca de soro de queijo fornecida na forma líquida, obtendo-se resultados bastante significativos, pois os suínos alimentados com soro de queijo não apresentaram diferenças $(\mathrm{P}<0,05)$ em desempenho e características de carcaça.
O setor do leite no Brasil é um dos mais importantes dentre as atividades agroindustriais, tanto no aspecto econômico quanto no social. É um segmento industrial bastante diversificado no âmbito nacional; encontrando-se presente nas mesmas, empresas de laticínios de diversos portes, variando de empresas ditas de fundo de quintal (beneficiadoras de volumes reduzidos de Leite) até grandes multinacionais e cooperativas centrais capazes de processar um montante diário de centenas de milhares de litros de leite, conforme cita (GOMES, 2012).

São três os subprodutos gerados pelas indústrias de laticínios sob a forma de efluente industrial: o soro, o leitelho (na desleitagem, onde há a retirada da parte líquida do creme batido, conforme descrevem (JERÔNIMO; SOUSA, 2012; VOGELAAR, 1997). Esse líquido é denominado leitelho e após um processo bem feito, apresenta-se de cor azulada). E o leite ácido. Destes, o primeiro é o de maior importância, tanto pelo volume produzido (cerca de 9L por $\mathrm{Kg}$ de queijo produzido) e pela própria característica de matéria-prima de qualidade e de amplo espectro de possibilidades de reutilização, quanto pelo seu enorme poder poluente.

O reaproveitamento do soro do queijo reduz os custos com o tratamento de efluentes, além de agregar valor quando utilizado na cadeia produtiva (GUIMARÃES et al., 2010).

A atividade de laticínios descarrega os resíduos em sua maioria orgânica, na água. Na pesquisa de Pomeroy et al. (2011), menciona-se que a importância que tem adquirido o lacto soro ou soro de queijo nos últimos anos, acontece por dois fatores, quais sejam: a poluição que causa nas águas dos rios e esgotos, quando é lançado nelas sem o devido tratamento, cada vez em maior quantidade pelo aumento da produção de queijo nos últimos anos e, contraditoriamente, porque esse "resíduo" tem um alto valor nutritivo.

\section{CONSIDERAÇÕES FINAIS}

O soro do leite é um subproduto de alto potencial poluidor, e as empresas perceberam que agregando valor a esse subproduto derivado do leite tem-se uma alternativa viável economicamente, além de reduzir os custos com o tratamento de efluentes.

É um subproduto com elevado valor nutricional que pode ser reinserido na cadeia produtiva na forma de bebidas lácteas e na alimentação animal.

A garantia de uma gestão sustentável no processo produtivo do queijo passa pela necessidade de conscientização dos empresários deste segmento, bem como da instalação e/ou adequação de sistemas de tratamento eficientes dos resíduos e efluentes gerados em todas as etapas do processo.

\section{REFERÊNCIAS BIBLIOGRÁFICAS}

ASSOCIAÇÃO BRASILEIRA DAS INDÚSTRIAS DE QUEIJO - ABIQ. Queijos no Brasil. Disponível em:<http://www.abiq.com.br/nutricao_queijosbrasil_ant. asp.>. Acesso em: 20 jul. 2014.

BARANA, A. C.; LIMA, R. C.; BOTELHO, V. B.; SIMÕES, D. R. Desenvolvimento de uma bebida láctea fermentada feita com soro ácido de queijo quark. Revista Verde, Mossoró, v. 7, n. 5, p. 13-21, dez. 2012 (Edição 
Especial). Disponível em: <http://www.gvaa.com.br/revista/index.php/RVADS/arti cle/view/1332.>. Acesso em: 20 jul. 2015.

BATISTA, L. C.; MORAES, N. A. C.; ABRAÃO, J. dos S.; NACHTIGALL, A. M.; SILVA, D. B. da.; VILAS BOAS, B. M.; COLPA, P. C. APROVEITAMENTO DE SORO DE QUEIJO: aceitação em doce de leite pastoso. JORNADA CIENTÍFICA E TECNOLÓGICA, 5., SIMPÓSIO DE PÓS-GRADUAÇÃO DO IFSULDEMINAS, 2.,2013, Inconfidentes. Anais... Inconfidentes: IFSULDEMINAS, 2013. Disponível em:<

https://jornada.ifsuldeminas.edu.br/index.php/jcinc/jcinc /paper/viewFile/55/64>. Acesso em: 27 jul. 2015.

BIASUTTI, E. A. R. Otimização das condições da hidrólise enzimática das proteínas do soro de leite para obter elevado teor de oligopeptídeos: utilização da subtilisina e da pancreatina. 2006. 88f. Dissertação (Mestrado em Ciência de Alimentos) - Faculdade de Farmácia, Universidade Federal de Minas Gerais, Belo Horizonte MG, 2006.

Disponível em:<www.bibliotecadigital.ufmg.br/dspace/.../disserta_ o_final_eliza.pdf?>. Acesso em: 20 jul. 2015.

BRASIL. Ministério da Agricultura, do Abastecimento e da Reforma Agrária. Portaria $\mathrm{n}^{\circ}$ 146, de 7 de março de 1996. Regulamentos Técnicos de Identidade e Qualidade dos Produtos Lácteos. Diário Oficial [da] República do Brasil, Brasília, 11 mar.1996. Disponível em:<http://www.sfdk.com.br/Imagens/lei/MA\%20$\%$ 20Portaria\%20146.htm>. Acesso em: 20 jul. 2015.

COSTA, C. M.; et., al. Soro do leite e os danos causados ao meio ambiente. X Encontro Brasileiro sobre adsorção, Guarujá - SP, 2014. Disponível em: <https://www2.cead.ufv.br/sgal/files/apoio/saibaMais/sa ibaMais2.pdf.>. Acesso em: 20 jul. 2015.

DAMATO, M. e MACUCO, P. Proposta metodológica para avaliação e mitigação de impactos ambientais decorrentes da implantação de obras de saneamento Básico. XXVIII Congreso Interamericano de Ingeniería Sanitária y Ambiental. Cancún, México, 2002. Disponível <http://www.bvsde.paho.org/bvsaidis/mexico26/viii016.pdf.>. Acesso em: 20 jul. 2015.

FARIZOGLU, B.; et al. Simultaneous removal of C, N, P from cheese whey by jet loop membrane bioreactor (JLMBR). J. Hazard. Mater. 146 (1-2), 399-407. 2007. Disponível em: <http://www.ncbi.nlm.nih.gov/pubmed/17267102.>. Acesso em: 20 Jul. 2015.

FRANCO, R. L. M. Recuperação e concentração das proteínas do soro de leite das queijarias do município de Nossa Senhora de Lourdes/Sergipe visando o desenvolvimento sustentável da região. 2006. 109 f. Dissertação (Mestrado em Meio Ambiente) Universidade Federal de Sergipe, São Cristóvão - SE,
$2006 . \quad$ Disponível em:

$<200.17 .141 .110 /$ pos/prodema/files/dis2006/REGIVANI A_FRANCO.pdf.>. Acesso em: 20 jul. 2015.

GOMES, S. T. Produção de leite no Brasil. Disponível em: $<$ http://www.ufv.br/der/docentes/stg/stg_artigos/Art_ 051\%20\%20PRODU\%C7\%C3O\%20DE\%20LEITE\%2 0NO\%20BRASI L\%20(3-10-91).pdf>. Acesso em: 20 jun. 2015.

GUIMARÃES, P. M. R.; TEIXEIRA, J. A.; DOMINGUES, L. Fermentation of lactose to bio-ethanol by yeasts as part of integrated solutions for the valorisation of cheese whey. Biotechnology Advances, p. 375-384, 2010. Disponível em: <http://www.sciencedirect.com/.../pii/S07349750100002 24.>. Acesso em: 20 jul. 2015.

IPEA. Poluição Industrial no Brasil, IPEA/IPLAN. Série Estudos para o Planejamento, n. 12, Brasília: IPEA, 1975.

JERONIMO, C. E.; SOUSA, J. F. Valorização e Aproveitamento de Subprodutos Lácticos: Extração de Proteínas e Hidrogenação Catalítica da Lactose. TECNO-LÓGICA, Santa Cruz do Sul, v. 16, n. 1, p. 1118, jan./jun. 2012. Disponível em:< http://online.unisc.br/seer/index.php/tecnologica/article/ view/2653/2093>. Acesso em: 27 jul. 2015.

JERÔNIMO, C. E. M.; COELHO, M. S.; MOURA, F. N.; ARAUJO, A. B. A. Qualidade ambiental e sanitária das indústrias de laticínios do Município de Mossoró-RN. Rev. Elet. em Gestão, Educação e Tecnologia Ambiental, v.7, n. 7, p. 1349-1356, mar.-ago., 2012. Disponível em: $<$ http://cascavel.ufsm.br/revistas/ojs2.2.2/index.php/reget/article/viewFile/5751/3599>. Acesso em: 20 jul. 2015.

MAGANHA, M. F. B. Guia técnico ambiental de produtos lácteos. São Paulo: CETESB, 2006. Disponível em:<http://www.abepro.org.br/.../ENEGEP2012_TN_S TO_165_961_20156. pdf.>. Acesso em: 25 jul. 2015.

MARTINS, T. D. D.; PIMENTA FILHO, E. C.; COSTA, R. G.; SOUZA, J. H. M. de. Soro de queijo líquido na alimentação de suínos em crescimento. Centro de Ciências Agrárias - Universidade Federal do Ceará. Revista Ciências Agronômica, v. 39, n. 02, p. 301-307, Abr.- $\quad$ Jun., $2008 . \quad$ Disponível em:<http://www.ccarevista.ufc.br/seer/index.php/ccarevi sta/article/view/64/60>. Acesso em : 25 jul. 2015.

MATTOS, A. L. A.; FIGUEIREDO, M. C. B. de; CAVALCANTE, J.B. relatório de avaliação dos impactos das tecnologias geradas pela EMBRAPA. Fortaleza - CE, 2013. Disponível em:< bs.sede.embrapa.br/.../relatorios/florestas_2012_eucalypt usbenthamii.pdf>. Acesso em: 25 jul. 2015.

Ministério da Integração Nacional. Secretaria de Infraestrutura Hídrica. Unidade de Gerenciamento do 
Pró-água/Semiárido. Diretrizes ambientais para projeto e construção de barragens e operação de reservatórios. Brasília: Bárbara Bela Editora Gráfica e Papelaria Ltda., $2005 . \quad$ Disponível em: <http://www.integracao.gov.br/c/document_library/get_f ile?uuid...a9ee.>. Acesso em: 25 jul. 2015.

MOREIRA, V. E.; SARAIVA, C. B.; MAGALHÃES, F. A. F. R. Produção de queijo artesanal da Serra da Canastra: resíduos gerados e seus destinos. Seminário de Iniciação Científica e Tecnológica, Belo Horizonte, 2012. Disponível em: <http://www.revistadoilct.com.br/rilct/article/viewFile/2 64/274.>. Acesso em: 25 jul. 2015.

NADAI, B. L.; et al. Potencialidade de Valorização do Resíduo da Cadeia do Leite do Oeste do Paraná na Produção de Biomassa Microbiana. III Encontro Paranaense de Engenharia e Ciência, Toledo-PR, 2013. Disponível <http://www.unioeste.br/eq/iiiepec/artigos/Trab04Nadai\%20et\%20al.pdf.>. Acesso em: 25 jul. 2015.

OZMIHCI, S.; CARGI, F. Effects of feed sugar concentration on continuous ethanol fermentation of cheese whey powder solution (CWP). Enzyme and Microbial Technology, p.876-880, july, 2007. Disponível em:<http://www.sciencedirect.com/.../pii /907002505>. Acesso em: 25 jul. 2015.

PAULA, J. C. J.; et al. Aproveitamento de soro de queijo de coalho na elaboração de bebida láctea pasteurizada. Artigo Técnico Revista do Instituto de Laticínios Cândido Tostes, v.67, n.387, 2012. Disponível em:<http://www.revistadoilct.com.br/rilct viewFile/246/256.> . Acesso em: 25 jul. 2015.

POMEROY, S.B.; BURSTEIN, S. M.; DONLAN, W.; ROBERTS, J. T.; TANDY, D. Ancient Greece: a political, social and cultural history. New York and Oxford: Oxford University, Press, 2011. 592p.

RESENDE, M. de F.S. de Queijo Minas artesanal da Serra da Canastra: influência da altitude e do nível de cadastramento das queijarias nas características físicoquímicas e microbiológicas, 2010. 72f. Dissertação
(Mestrado em Ciência Animal) - Escola de Veterinária, Universidade Federal de Minas Gerais, Belo Horizonte MG, 2010. Disponível em: <www.vet.ufmg.br/DOWNLOAD.php?..queijo_minas_a rtesanal_da_serra.>. Acesso em: 25 jul. 2015.

RUAS, F. I. P. Gestão das águas residuais pré-tratadas de queijarias. 2012. 119 f. Dissertação (Mestrado em Engenharia do Ambiente) - Instituto Politécnico de Beja - Escola Superior Agrária, Beja - Lisboa, 2012. Disponível em: <http://biblioteca.universia.net/html_bura/ficha/params/t itle/gest\%C3\% A3o-aguas-residuais-pré-tratadas queijarias/id/56593069. html.>. Acesso em: 25 jul. 2015.

SARAIVA, C. B.; et al. Aspectos ambientais da produção do queijo minas artesanal. Rev. Inst. Latic. "Cândido Tostes", Minas Gerais, 2012. Disponível em:<www.abepro.org.br/.../enegep2011_

TN_STO_143_903_18760.pdf.>. Acesso em: 22 jul. 2015.

SERPA, L.; PRIAMO, W. L.; REGINATTO, V. Destino Ambientalmente Correto a Rejeitos de Queijaria e Análise de Viabilidade Econômica. $2^{\text {nd }}$ International Workshop | Advances in Cleaner Production. Key Elements For a Sustainable World: Energy, Water and Climate Change. São Paulo, 2009.

Disponível em: $<$ http://www.advancesincleanerprodu duction.net/.../v.\%20reginatto\%20-\%20resum.>. Acesso em: 20 jul. 2014.

SUZART, C. A. G., DIAS, J. C. T. Desenvolvimento tecnológico de aguardente de soro de queijo. Projeto Bolsa BITEC, IEL, SEBRAE e CNPQ, 2007. Disponível em: <www.unioeste.br/eq/iiiepec/artigos

/Trab04-Nadai\%20et\%20al. pdf.>. Acesso em: 23 jul. 2015.

VOGELAAR, R. C.; PAWLOWSKY, U. Reaproveitamento do Soro do Queijo por Coagulação com Quitosana. In: Congresso Brasileiro de Engenharia Sanitária e Ambiental, 19., 1997, Rio de Janeiro. Anais... Rio de Janeiro, 1997. p. 370 - 378. Disponível em:< http://www.bvsde.paho.org/bvsacd/abes97/soro.pdf>. Acesso em: 27 jul. 2015. 